\title{
Sur la teneur en protéines et la digestibilité d'une paille de blé traitée par Trichoderma viride et Myrothecium verrucaria
}

\author{
A. LARWENCE et Samia ABADA \\ Institut National Agronomique, Département de Zootechnie \\ El-Harrach (Algérie)
}

\begin{abstract}
Résumé
Nous avons étudié en milieu semi-solide (taux d'humidité 80,84 et 87 p. 100) et pour trois valeurs de $\mathrm{pH}(4,5$ et 6$)$, la possibilité d'améliorer la valeur nutritive (teneur en protéines et digestibilité) d'une paille de blé, à l'aide de deux souches de champignons filamenteux : Trichoderma viride et Myrothecium verrucaria.

Sur la paille traitée obtenue au bout de huit jours de culture sont évaluées : la teneur en matière sèche, en protéines et en composés pariétaux ainsi que la digestibilité in sacco.

Il apparaît que :

1) La teneur en cellulose Van Soest des pailles traitées diminue pour les deux organismes par rapport aux témoins paille non ensemencée. Toutefois, la diminution est plus forte pour les échantillons traités avec Trichoderma (12 points contre 8 pour Myrothecium). Cette dégradation de la cellulose a entraîné une augmentation de la teneur en lignine de 8 et 1 points respectivement pour Trichoderma et pour Myrothecium.
\end{abstract}

2) La teneur en protéines des échantillons traités augmente en moyenne respectivement de 3,3 et de $4,7 \mathrm{~g} / 100 \mathrm{~g}$ de MS pour Trichoderma et pour Myrothecium, amenant la teneur totale en protéines des échantillons à 7,1 et $8,4 \mathrm{~g} / 100 \mathrm{~g}$ de MS. Ces teneurs correspondent à un rendement de 0,31 et $0,60 \mathrm{~g}$ de protéines mycéliennes $/ \mathrm{g}$ de cellulose utilisée.

3) La digestibilité des échantillons témoins s'établit en moyenne à 59 p. 100 contre 54 p. 100 pour Trichoderma. Par contre, celle des échantillons traités avec Myrothecium est plus élevée (61 p. 100); notamment avec le pH 6 et une humidité de $87 \mathrm{p} .100$, on atteint $67 \mathrm{p} .100$ de digestibilité.

Les valeurs de la digestibilité évoluent dans le même sens que la teneur des échantillons en protéines et en cellulose et en sens inverse pour la teneur en lignine et pour les pertes en matière sèche.

Mots clés: Trichoderma viride, Myrothecium verrucaria, paille de blé traitée, digestibilité in sacco, teneur en protéines.

\section{Introduction}

Dans de nombreux pays, la diminution du rapport $\frac{\operatorname{SAU}^{(*)}}{\text { Nombre d'habitants }}(0,3$ en Algérie) atteint des seuils qui obligent le planificateur à consacrer l'essentiel des terres

(*) SAU : surface agricole utile. 
aux productions végétales destinées à l'alimentation humaine. Le développement de l'élevage des ruminants producteurs de lait et de viande (dont le fumier qui en résulte est nécessaire au maintien de la fertilité du sol) est menacé par manque de terres susceptibles de porter des cultures fourragères.

Aussi, l'utilisation des pailles dans l'alimentation des ruminants suscite-t-elle de vifs intérêts (Kiflewahid, Potrs \& Drysdale, 1982). Elle permettrait de produire, d'un seul coup sur le même hectare, les denrées alimentaires destinées à l'homme et le fourrage pour le ruminant. Malheureusement, la digestibilité des pailles est faible car elles sont riches en composés pariétaux, pauvres en sucres, en azote et en vitamines (Hoden, 1972 ; Xande, 1978 a ; Horton, Nicholson \& Christensen, 1982). Classiquement, l'amélioration de la valeur nutritive des pailles est obtenue par une complémentation azotée et minérale correcte (XANDE, 1978 b) ou par des traitements chimiques (pour rendre les composés pariétaux plus digestibles) notamment à la soude (WILKINSON \& Gonzalez, 1978 ; Kategile \& Frederiksen, 1978 ; Ben-Ghedalia \& Miron, 1981 ; Dulphy et al., 1982) et à l'ammoniac (WaAgePetersen \& ThOMSen, 1977 ; OıI \& Mowat, 1979 ; Borhami, Sundstøl \& Garmo, 1982). La digestibilité augmente alors de 8 à 12 points.

Néanmoins, cet accroissement de la digestibilité ne supprime pas l'apport d'un concentré adéquat dans la ration (KATEGILE, 1979 ; CoRdesse \& TABA-TABAI, 1981 ; Williams, Mac Dearmid \& InNes, 1983) dont la production pourrait se révéler difficile.

L'enrichissement en protéines de ces pailles par le biais de micro-organismes pourrait représenter une autre' possibilité de complémentation et d'amélioration, sans faire appel à des hectares supplémentaires de terres. Dans cette optique, et dans l'état actuel des connaissances, les champignons ligninolytiques ne conviennent pas car le système ligninolytique est réprimé en présence d'azote (ZADraZIL \& BrUnNERT, 1982). Les champignons cellulolytiques par contre, enrichissent effectivement la paille en protéines ; mais une activité cellulolytique trop forte peut entraîner une diminution de digestibilité de la paille traitée (Demeyer \& Vervaeke, 1985).

Nous avons donc voulu étudier, chez le mouton, à l'aide de la technique des sachets en nylon, la digestibilité d'une paille de blé après traitement (dans des conditions différentes de $\mathrm{pH}$ et d'humidité) par deux souches de moisissures cellulolytiques: Trichoderma viride connu pour sa forte activité cellulolytique et Myrothecium verrucaria moins actif vis-à-vis de la cellulose.

\section{Matériel et méthodes}

\section{A. Souches de champignons utilisées}

Il s'agit de deux souches sauvages Trichoderma viride et Myrothecium verrucaria isolées du sol algérien par une méthode classique de dilution (LARPENT \& LARPENTGourgaud, 1970). 


\section{B. Procédé de culture et traitement des pailles traitées}

Les cultures sont menées en milieu semi-solide, en présence de trois taux d'humidité $(80,84$ et 87 p. 100). Pour chaque taux, trois valeurs de $\mathrm{pH}$ sont testées $(4,5$ et 6), soit 9 échantillons par souche.

Dans une boîte de pétri de $210 \mathrm{~mm}$ de diamètre, $16 \mathrm{~g}$ de paille (dosant $92 \mathrm{p} .100$ de MS et 3,7 p. 100 de MAT) finement broyée sont amenés à chaque taux d'humidité avec la solution minérale Staron (1984) ajustée aux différents $\mathrm{pH}$ avec une solution normale d'acide ortho-phosphorique. Compte tenu des différences d'humidité, les solutions minérales sont calculées de telle sorte que les quantités d'éléments soient identiques dans chaque boîte de pétri.

Les boîtes de pétri ainsi préparées sont stérilisées à l'autoclave pendant 30 minutes à $120^{\circ} \mathrm{C}$. Pour chaque taux d'humidité et pour un $\mathrm{pH}$ de 5 , un témoin non ensemencé est réalisé et traité dans les mêmes conditions que précédemment. Par addition de la solution minérale de sulfate d'ammonium enrichie du mycélium d'insémination (culture de trois jours), tous les échantillons sont amenés à la teneur de 10 p. 100 en matières azotées totales par rapport à la matière sèche $(3,7$ p. 100 natifs de la paille ; 6,3 p. 100 apportés par la solution minérale).

Après huit jours de culture à $28^{\circ} \mathrm{C}$, la paille obtenue est traitée selon le schéma 1.

\section{SCHÉMA 1}

Traitement des échantillons.

Treatment of straw samples.

Prélèvement de $5 \mathrm{~g}$ : addition de

$25 \mathrm{ml}$ d'eau

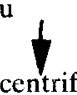

$10 \mathrm{mn}$ de mixage

$15 \mathrm{mn}$ de centrifugation

Ajustement du surnageant à $30 \mathrm{ml}$

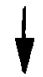

Dosage des protéines

Paille traitée

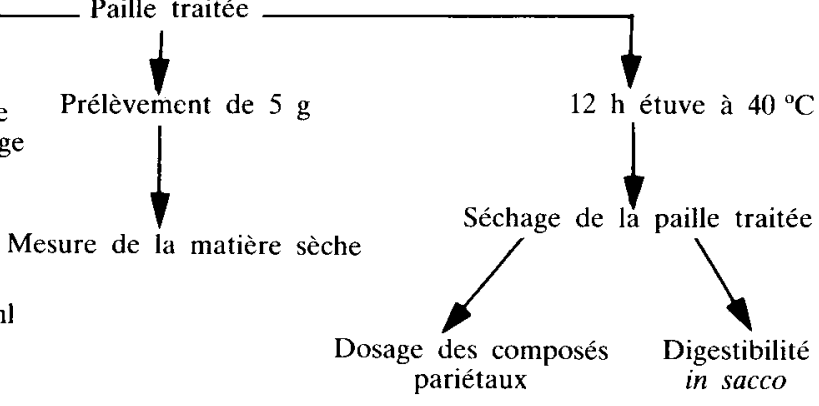

\section{Analyse}

Les composés pariétaux (NDF ; ADF ; cellulose ; hémicellulose et lignine) sont déterminés sur les échantillons avant et après traitement selon la méthode de VAN SOEST \& WINE (1967).

Les protéines vraies des $30 \mathrm{ml}$ de surnageant sont dosées sur une partie aliquote de $1 \mathrm{ml}$ selon la méthode de Lowry et al. (1951) (le réactif de Folin-Ciocalteu mis en 
présence d'une protéine est réduit en un complexe bleu de molybdène ; la lecture de la coloration est faite à $750 \mathrm{~nm}$ ) puis calculée pour $5 \mathrm{~g}$ de paille traitée (schéma 1), et enfin pour la totalité des pailles désincubées.

La méthode de Lowry et al. est recommandée pour le dosage des protéines mycéliennes (Raimbault, 1981).

Le pourcentage des matières totales du sulfate d'ammonium transformé en protéines par les moisissures (p. $100 \mathrm{MAT}_{1}$ ) est obtenue par l'expression :

$$
\text { p. } 100 \mathrm{MAT}_{1}=\frac{\text { Protéines Paille Traitée }(\mathrm{g}) \times 100}{6,3}
$$

La teneur en protéines de $100 \mathrm{~g}$ de paille traitée peut être alors facilement calculée. Dans ce calcul, nous considérons qu'au bout de huit jours de culture, les protéines natives de la paille ne sont pas dégradées.

\section{Mesures}

\section{Pertes en matière sèche}

Elles sont mesurées par pesée des échantillons avant et après culture.

\section{Digestibilité}

Elle est mesurée in sacco pendant 48 heures dans le rumen de trois moutons (6 sachets par échantillon) de race Ouled-Djellal recevant une ration composée de foin de vesce-avoine de qualité moyenne et de $200 \mathrm{~g}$ de tourteau de soja 50. La prise d'échantillon est de $3 \mathrm{~g}$ et les caractéristiques des sachets sont celles proposées par Demarquilly \& Chenost (1969).

\section{Résultats}

Après 24 à 36 heures de culture, la surface des échantillons de paille présente de nombreux boutons blancs de mycélium. L'envahissement total du milieu commence au bout de 48 heures; à la fin de la culture, la paille est prise en masse et présente un aspect grumeleux.

\section{A. Teneur en matière sèche des échantillons de paille traitée}

Au départ de la culture, la teneur en matière sèche des préparations était de 20 , 16 et 13 p. 100 . A la fin de la période de culture ( 8 jours), elle est tombée en moyenne respectivement à 16,13 et 11 p. 100 indistinctement pour les deux souches de champignons (tabl. 1). Cet enrichissement en eau n'est pas affecté par le pH ; elle s'explique par la production d'eau métabolique par les organismes. 


\section{TABleau 1}

Teneur en matière sèche des pailles traitées.

Dry matter content of treated straw.

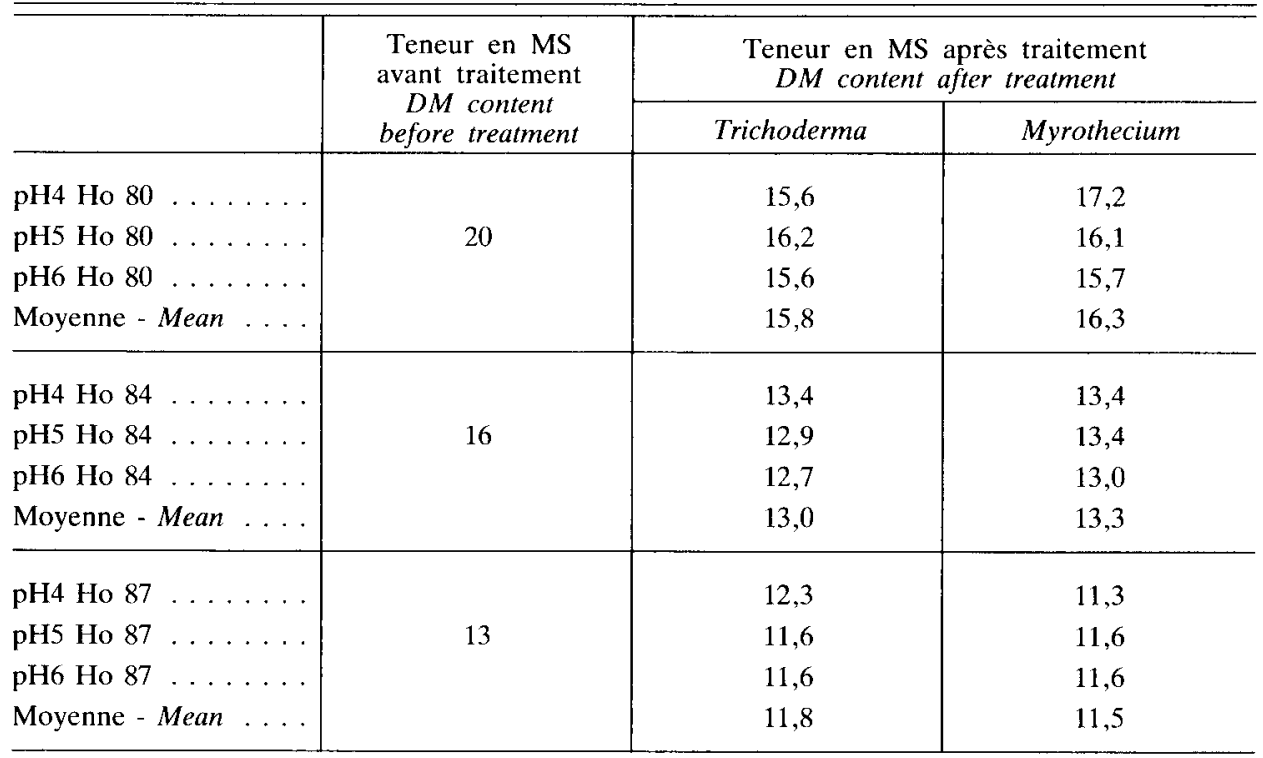

Ho 80

Ho 84 Humidité 80,84 et 87 p. 100 - Moisture content.

Ho 87

\section{B. Teneur en composés pariétaux des pailles traitées}

Le tableau 2 présente d'une part, la quantité de matière sèche solubilisée par la solution NDF ainsi que les valeurs de NDF et d'autre part, la proportion de cellulose, d'hémicelluloses et de lignine que renferme le résidu NDF.

Comparativement aux témoins autoclavés mais non ensemencés, la matière sèche soluble des pailles traitées augmente en moyenne de 6,2 et de 2,7 points respectivement pour les échantillons Trichoderma et Myrothecium. Cet accroissement s'explique par l'apport en éléments solubles du mycélium; il en résulte donc une diminution de la teneur en NDF qui s'établit à 6,6 et 3,3 points respectivement.

Il est intéressant d'analyser la composition centésimale de la paroi végétale : il apparaît que la cellulose est le seul composant de la paroi utilisé par les deux souches de moisissures. En moyenne, la "ponction » effectuée par Trichoderma est plus forte ( -12 points) que celle effectuée par Myrothecium ( -8 points). Cette diminution de la teneur en cellulose du résidu NDF entraîne une légère augmentation des teneurs en hémicelluloses (environ 2 points) mais une forte progression de la lignine notamment pour les échantillons Trichoderma ( 8,5 points) et à moindre degré pour les échantillons Myrothecium (1,1 point). 


\section{TABleaU 2}

Teneur en composés pariétaux des pailles avant et après traitement.

Cell wall content before and after treatment.

\begin{tabular}{|c|c|c|c|c|c|c|c|c|c|c|}
\hline \multicolumn{5}{|c|}{$\begin{array}{l}\text { Partition des } 100 \mathrm{~g} \text { de } \mathrm{MS} \\
100 \mathrm{~g} \text { of } D M \text { partition }\end{array}$} & \multicolumn{6}{|c|}{$\begin{array}{l}\text { Composition des parois végétales }(\%) \\
\text { Neutral detergent fibre composition }(\%)\end{array}$} \\
\hline \multirow[b]{2}{*}{$\begin{array}{l}\text { Paille autoclavée } \\
\text { Untreated straw }\end{array}$} & \multicolumn{2}{|c|}{$\begin{array}{l}\text { MS solubilisée } \\
\text { Solubilised DM }\end{array}$} & \multicolumn{2}{|c|}{ NDF } & \multicolumn{2}{|c|}{$\begin{array}{l}\text { Cellulose } \\
\text { Fibre }\end{array}$} & \multicolumn{2}{|c|}{ Hemicelluloses } & \multicolumn{2}{|c|}{$\begin{array}{l}\text { Lignine } \\
\text { Lignin }\end{array}$} \\
\hline & \multirow{5}{*}{\multicolumn{2}{|c|}{$\begin{array}{l}27,7 \\
26,9 \\
26,4 \\
27,0\end{array}$}} & \multirow{5}{*}{\multicolumn{2}{|c|}{$\begin{array}{l}72,3 \\
73,1 \\
73,6 \\
73,0\end{array}$}} & \multirow{5}{*}{\multicolumn{2}{|c|}{$\begin{array}{l}56,8 \\
56,9 \\
56,4 \\
56,7\end{array}$}} & \multirow{5}{*}{\multicolumn{2}{|c|}{$\begin{array}{l}38,4 \\
37,1 \\
36,1 \\
37,2\end{array}$}} & \multirow{5}{*}{\multicolumn{2}{|c|}{$\begin{array}{l}8,6 \\
8,3 \\
7,6 \\
8,2\end{array}$}} \\
\hline pH5 Но $80 \ldots$ & & & & & & & & & & \\
\hline pH5 Ho 84 & & & & & & & & & & \\
\hline pH5 Ho $87 \ldots \ldots$ & & & & & & & & & & \\
\hline Moyenne-Mean & & & & & & & & & & \\
\hline $\begin{array}{l}\text { Pailles traitées } \\
\text { Treated straw }\end{array}$ & TV & MV & TV & MV & TV & MV & TV & MV & TV & MV \\
\hline pH4 Ho 80 & 33,9 & 29,9 & 66,1 & 71,1 & 49,6 & 48,5 & 36,3 & 40,1 & 13,3 & 9,4 \\
\hline pH5 Ho 80 & 32,8 & 30,0 & 67,2 & 70,0 & 45,8 & 48,0 & 31,4 & 39,7 & 15,6 & 8,8 \\
\hline pH6 Ho 80 & 33,1 & 29,5 & 66,9 & 70,5 & 45,9 & 48,1 & 40,6 & 39,4 & 12,4 & 9,2 \\
\hline pH4 Ho 84 & 32,8 & 30,9 & 67,2 & 69,1 & 47,2 & 48,2 & 41,4 & 38,9 & 16,6 & 9,3 \\
\hline pH5 Ho 84 & 33,6 & 29,4 & 66,4 & 70,6 & 37,9 & 49,3 & 41,1 & 39,8 & 22,3 & 9,3 \\
\hline pH6 Ho 84 & 33,2 & 31,2 & 66,8 & 68,8 & 40,7 & 48,7 & 40,6 & 38,4 & 16,1 & 9,6 \\
\hline pH4 Ho 87 & 34,5 & 28,4 & 65,5 & 71,6 & 45,5 & 47,1 & 42,6 & 40,2 & 17,2 & 9,6 \\
\hline pH5 Ho 87 & 32,9 & 29,4 & 67,1 & 70,6 & 42,8 & 50,6 & 41,3 & 38,1 & 18,2 & 9,5 \\
\hline pH6 Но 87 & 31,8 & 29,6 & 68,2 & 70,4 & 46,8 & 50,3 & 39,7 & 38,1 & 18,9 & 9,1 \\
\hline Moyenne - Mean . . & 33,2 & 29,7 & 66,4 & 70,3 & 44,7 & 48,7 & 39,4 & 39,2 & 16,7 & 9,3 \\
\hline
\end{tabular}

TV : Trichoderma viride.

MV: Myrothecium verrucaria.

Ho 80

Ho 84 Taux d'humidité 80,84 et 87 p. 100 - Moisture content.

Ho 87

Le $\mathrm{pH}$ et le taux d'humidité ne semblent pas affecter la composition en paroi des pailles traitées sauf relativement pour les échantillons Myrothecium pH 5 et pH 6 du taux d'humidité 87 p. 100 pour lesquels nous notons une plus faible dégradation de la cellulose $(2,1$ points en moyenne).

\section{Pertes en matière sèche en cours de culture}

Les moisissures, pour tirer l'énergie nécessaire à leur croissance, dégradent le substrat paille; il en résulte dors des pertes de matière sèche dont les valeurs sont présentées dans le tableau 3. Pour $100 \mathrm{~g}$ de paille incubée, elles s'établissent en moyenne à 9,36 et à 7,5 p. 100 respectivement pour les échantillons Trichoderma et Myrothecium. Concernant ce dernier organisme, nous avons enregistré des pertes de matière sèche plus faibles pour les échantillons du taux d'humidité 87 p. 100 (6,2 p. 100 contre 7,5 p. 100 en moyenne pour l'ensemble des échantillons). Ces pertes qui intéressent essentiellement les composants cellulosiques de la paroi (tabl. 2) ne sont pas plus élevées que celles que l'on relève classiquement pour les ensilages. 


\section{Tableau 3}

Pertes de matière sèche après traitement.

Dry matter losses after treatment.

\begin{tabular}{|c|c|c|c|c|c|c|c|}
\hline & \multirow[t]{2}{*}{$\begin{array}{c}\text { MS de } \\
\text { paille } \\
\text { incubée }(\mathrm{g}) \\
\text { DM of } \\
\text { incubated } \\
\text { straw }(\mathrm{g})\end{array}$} & \multicolumn{2}{|c|}{$\begin{array}{c}\text { MS résiduelle } \\
\text { après traitement } \\
\text { Residual } D M \\
\text { after treatment }(g)\end{array}$} & \multicolumn{2}{|c|}{$\begin{array}{l}\text { Pertes en MS }(\mathrm{g}) \\
\text { DM losses }(\mathrm{g})\end{array}$} & \multicolumn{2}{|c|}{$\begin{array}{c}\text { Pertes en MS } \\
(\%) \\
D M \text { losses }(\%,\end{array}$} \\
\hline & & TV & MV & TV & MV & TV & MV \\
\hline pH4-Ho 80 & 14,70 & 13,41 & 13,43 & 1,29 & 1,27 & 8,83 & 8,63 \\
\hline pH5-Ho 80 & 14,70 & 13,34 & 13,46 & 1,36 & 1,24 & 9,22 & 8,43 \\
\hline pH6-Ho 80 & 14,70 & 13,23 & 13,45 & 1,47 & 1,25 & 10,00 & 8,50 \\
\hline pH4-Ho 84 & 14,70 & 13,41 & 13,78 & 1,29 & 0,92 & 8,83 & 6,25 \\
\hline pH5-Ho 84 & 14,70 & 13,33 & 13,49 & 1,37 & 1,21 & 9,32 & 8,23 \\
\hline PH6-Ho 84 & 14,70 & 13,27 & 13,39 & 1,43 & 1,31 & 9,72 & 8,91 \\
\hline pH4-Ho 87 & 14,70 & 13,26 & 13,67 & 1,44 & 1,03 & 9,80 & 7,00 \\
\hline pH5-Ho 87 & 14,70 & 13,35 & 13,95 & 1,35 & 0,75 & 9,18 & 5,10 \\
\hline pH6-Ho $87 \ldots \ldots$ & 14,70 & 13,32 & 13,75 & 1,38 & 0,95 & 9,38 & 6,46 \\
\hline Moyenne - Mean ... & 14,70 & 13,32 & 13,60 & 1,37 & 1,10 & 9,36 & 7,50 \\
\hline
\end{tabular}

TV : Trichoderma viride.

MV : Myrothecium verrucaria.

Ho 80

Ho 84 Humidité 80,84 et 87 p. 100 - Moisture content.

Ho 87

\section{Teneur en protéines des pailles traitées}

Pour une teneur en matières azotées totales au départ de la culture de 10 p. 100 (3,7 p. 100 de protéines natives de la paille et 6,3 p. 100 apportées sous forme de sulfate d'ammonium), la teneur finale en protéines des échantillons dépend du rendement de la transformation de l'azote du sulfate d'ammonium en protéines mycéliennes. Ce rendement s'établit en moyenne à 52,9 et à 74,1 p. 100 respectivement pour les échantillons Trichoderma et Myrothecium; ces valeurs correspondent à des quantités de protéines vraies de 3,3 et 4,7 g (tabl. 4). En considérant que les protéines natives de la paille n'ont pas été dégradées par les champignons au cours des huit jours de culture, nous aboutissons respectivement à une teneur totale en protéines de 7,1 et de $8,4 \mathrm{~g} /$ $100 \mathrm{~g}$ de matière sèche de paille traitée.

La quantité de protéines mycéliennes synthétisées par gramme de cellulose dégradée varie du simple au double pour les deux organismes. Ainsi, s'établit-elle à 0,31 et à $0,60 \mathrm{~g}$ respectivement pour les échantillons Trichoderma et Myrothecium. Les valeurs les plus élevées s'observent pour les échantillons Myrothecium au taux d'humidité de 87 p. 100. Myrothecium verrucaria semble préférer des taux d'humidité élevés. En revanche, pour Trichoderma, la synthèse de protéines mycéliennes la plus élevée est observée pour le taux d'humidité de 80 p. 100 (tabl. 4). 


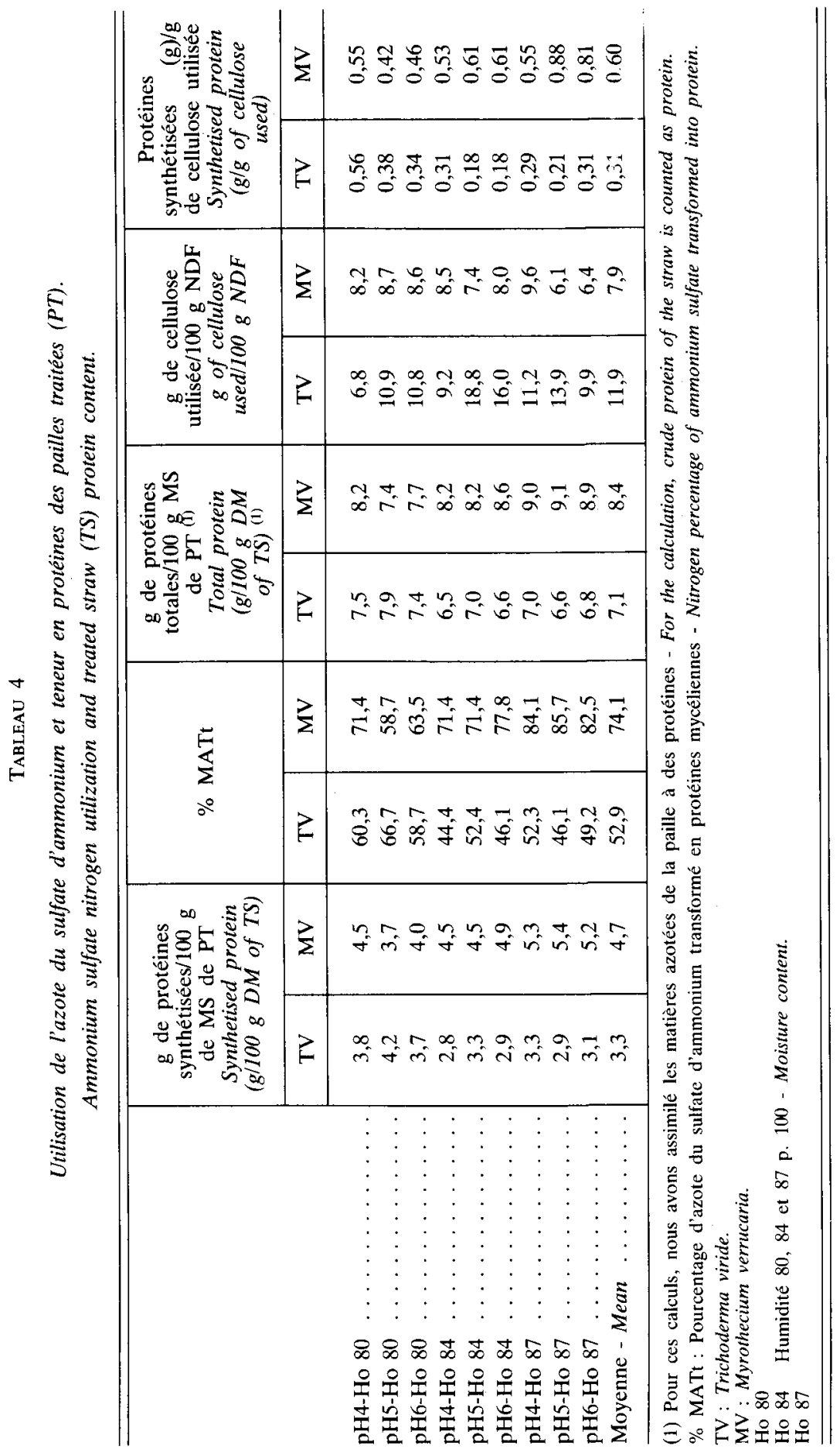




\section{E. Digestibilité des échantillons de paille traitée}

Le tableau 5 présente les résultats de digestibilité des pailles traitées par les deux organismes, dans différentes conditions de $\mathrm{pH}$ et d'humidité.

\section{TABLEAU 5}

Digestibilité in sacco des échantillons de paille avant et après traitement (\%).

In sacco digestibility of samples before and after treatment $(\%)$.

\begin{tabular}{|c|c|c|}
\hline $\begin{array}{l}\text { Témoins autoclavés } \\
\text { Untreated straw }\end{array}$ & \multicolumn{2}{|c|}{$\begin{array}{c}\text { Digestibilité }(\%) \pm \text { écart-type } \\
\text { Digestibility }(\%) \pm S d\end{array}$} \\
\hline $\begin{array}{l}\text { pH5-Ho } 80 \ldots \ldots \ldots \\
\text { pH5-Ho } 84, \ldots \ldots \ldots \\
\text { pH5-Ho } 87 \\
\text { Moyenne }- \text { Mean } \ldots \ldots \ldots \ldots \ldots\end{array}$ & \multicolumn{2}{|c|}{$\begin{array}{l}57,8 \pm 3,7 \\
59,8 \pm 3,8 \\
58,7 \pm 4,0 \\
58,8 \pm 0,9\end{array}$} \\
\hline $\begin{array}{l}\text { Pailles traitées } \\
\text { Treated straw }\end{array}$ & TV & MV \\
\hline 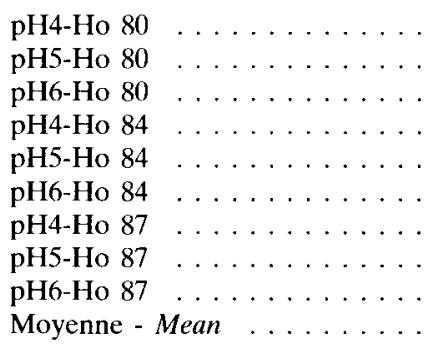 & $\begin{array}{l}53,7 \pm 3,0^{\mathrm{a}} \\
54,0 \pm 2,4^{\mathrm{a}} \\
53,0 \pm 3,2^{\mathrm{a}} \\
58,1 \pm 1,8^{\mathrm{a}} \\
53,5 \pm 3,5^{\mathrm{a}} \\
51,1 \pm 2,0^{\mathrm{a}} \\
54,3 \pm 1,9^{\mathrm{a}} \\
52,3 \pm 4,9^{\mathrm{a}} \\
54,4 \pm 2,5^{\mathrm{a}} \\
53,8 \pm 3,2\end{array}$ & $\begin{array}{l}60,3 \pm 2,9^{\mathrm{b}} \\
57,4 \pm 3,7^{\mathrm{a}} \\
59,2 \pm 4,1^{\mathrm{b}} \\
59,1 \pm 2,5^{\mathrm{a}} \\
62,4 \pm 3,0^{\mathrm{b}} \\
60,1 \pm 1,8^{\mathrm{b}} \\
60,9 \pm 4,5^{\mathrm{b}} \\
64,4 \pm 6,0^{\mathrm{b}} \\
66,6 \pm 5,6^{\mathrm{b}} \\
61,1 \pm 3,0^{\mathrm{b}}\end{array}$ \\
\hline
\end{tabular}

Sur une même ligne, les valcurs portant le même lettre ne sont pas significativement différentes (test de Student à $\mathrm{P}<0,05)$ - For the same line, values with the same superscript are not significantly different (Student's test $P<0,05)$.

TV : Trichoderma viride.

MV: Myrothecium verrucaria.

Ho 80

Ho 84 Humidité 80,84 et 87 p. 100 - Moisture content.

Ho 87

Pour les échantillons traités par Trichoderma, le taux d'humidité et le niveau de pH n'affectent pas dans l'ensemble la digestibilité qui s'établit en moyenne à 53,8 p. 100 , soit 5 points de moins que les échantillons témoins $(\mathrm{P}<0,01)$.

Pour ceux traités par Myrothecium, la digestibilité moyenne s'établit à 61,1 p. 100; elle est significativement différente d'une part de celle des témoins $(61,1$ contre $58,8$ p. $100 ; \mathrm{P}<0,05)$ et d'autre part de celle de Trichoderma $(61,1$ contre $53,8$ p. $100 ; \mathrm{P}<0,01)$. Pour ce dernier organisme, le taux d'humidité influence positivement la digestibilité ; ainsi le taux d'humidité de 87 p. 100 associé au pH 6, présente une digestibilité de 66,6 p. 100 . Notons par ailleurs que cet échantillon est le plus riche en cellulose (tabl. 2) et en protéines (tabl. 4). 


\section{Discussion}

Les objectifs que nous assignons à un tel procédé de valorisation des pailles dans l'alimentation du ruminant sont de deux ordres:

1) augmenter la digestibilité des pailles traitées dans les mêmes proportions que celle enregistrée pour un traitement classique à l'ammoniac (environ 10 points) ;

2) augmenter la teneur en protéines du substrat, de manière à diminuer ou à supprimer la part du concentré dans la ration. Ce dernier aspect est particulièrement important pour les pays dont le rapport $\frac{\text { SAU }}{\text { Nombre d'habitants }}$ est faible et qui doivent tout de même maintenir ou promouvoir l'élevage des ruminants.

\section{A. Amélioration de la teneur en protéines des pailles traitées}

Le ruminant, grâce aux micro-organismes qui vivent dans sa panse, est un valorisateur des fourrages pauvres car il synthétise des protéines de bonne qualité à partir d'une source d'azote simple et d'énergie, qui dans les conditions classiques d'alimentation dans les pays chauds, est apportée essentiellement par les parois végétales des fourrages pauvres ingérés.

Les nombreuses études consacrées à cet aspect de la nutrition du ruminant montrent que les quantités de protéines synthétisées dans le rumen lorsque les rations sont constituées de fourrages pauvres varient entre 8 et $13 \mathrm{~g}$ par $100 \mathrm{~g}$ de matière organique digestible (revue de DeMEYer \& VAN Nevel, 1986). Les calculs effectués à partir des résultats de CoRdesse \& TABA TABAI (1981) pour une paille traitée à l'ammoniac, la situe à $15 \mathrm{~g}$. Dans ces conditions, est-il nécessaire de «court circuiter » le ruminant pour produire ces protéines?

Selon Stakon (1984), le rendement moyen de bioconversion des champignons est de l'ordre de $60 \mathrm{p} .100$; en supposant une teneur en protéines du mycélium de $50 \mathrm{p}$. 100 , le rendement de synthèse serait de l'ordre de $30 \mathrm{p} .100$. Ce rendement moyen est en accord avec celui que nous obtenons pour les échantillons Trichoderma (31 p. 100). Avec Myrothecium qui métabolise dans nos conditions expérimentales très correctement cette source d'azote $(74 \mathrm{p} .100)$, le rendement de transformation de l'azote du sulfate d'ammonium en protéines mycéliennes s'établit à $60 \mathrm{p}$. 100 , soit le double de celui observé pour Trichoderma. En première analyse, ce dernier résultat semble surestimé ; cependant, le même auteur rapporte des rendements de bioconversion extrêmes, de 82 p. 100 pour Epicoccum Sp., Rhizocton Sp., et pour Trichoderma album.

Sur cette base, et en prenant comme rendement moyen de synthèse dans le rumen, $10 \mathrm{~g}$ de protéines par $100 \mathrm{~g}$ de matière organique digestible de fourrages pauvres, les deux souches de moisissures que nous avons testées transforment la cellulose en protéines mycéliennes avec un rendement 3 à 6 fois plus élevé.

Il semble logique d'arrêter ici notre comparaison car nous ne disposons pas d'informations sur le comportement in vivo de tels aliments. Néanmoins, nous pouvons nous attendre à une stimulation de la synthèse de protéines dans le rumen grâce aux vitamines, à l'énergie rapidement fermentescible, et aux protéines apportées par le mycélium. 
Par ailleurs, le taux protéique des échantillons traités peut-être amélioré puisque Iconomou (1982) ainsi que NoJAC (1984) rapportent des niveaux d'enrichissement de 26 p. 100 pour la paille et de 20 p. 100 pour la pulpe de betterave.

Il convient donc d'expérimenter des doses plus élevées d'azote en diversifiant la nature de la source.

\section{B. Niveau de digestibilité et teneur en composés pariétaux des pailles traitées}

La croissance des deux organismes s'effectue essentiellement aux dépens de la cellulose qui voit sa teneur diminuer de $21,1 \mathrm{~g}$ et de $14,1 \mathrm{~g}$ par $100 \mathrm{~g}$ de NDF, respectivement pour les échantillons Trichoderma et Myrothecium. Cette cellulose se tranforme partiellement en mycélium riche en protéines. Les pertes en cellulose ne correspondent évidemment pas aux pertes de matière sèche au cours de la culture qui sont plus faibles (respectivement 9,36 et $7,50 \mathrm{p}$. 100) ; la différence devrait correspondre très grossièrement au poids de mycélium qui s'est accumulé durant la culture. Dans ce cas, le poids de mycélium serait de 11,84 et $6,6 \mathrm{~g}$ respectivement pour les échantillons Trichoderma et Myrothecium. La teneur en éléments solubles dans la solution NDF (NDFS) devrait être plus élevée pour les échantillons Trichoderma; c'est bien ce que les résultats du tableau 2 nous révèlent (33,2 contre 29,7 pour Myrothecium et $27 \mathrm{~g}$ pour les témoins autoclavés).

L'enrichissement du résidu NDF en lignine, qui résulte de la consommation des constituants cellulosiques par les organismes, est gênant car la lignine est négativement corrélée avec la digestibilité ; à l'inverse, la digestibilité est en relation positive avec NDFS. Cependant, pour les échantillons Trichoderma, malgré une progression de 22,9 p. 100 de NDFS après traitement, il n'y a pas eu compensation de la diminution de la digestibilité résultant de l'augmentation de la teneur en lignine (103,6 p. 100) qui s'établit en moyenne à 53,8 p. $100 \pm 3,2$. Pour les échantillons Myrothecium, NDFS et la teneur en lignine progressent respectivement de 10,0 et de $13,4 \mathrm{p} .100$ établissant ainsi la digestibilité en moyenne à 61,1 p. $100 \pm 3,0$. La teneur en lignine a donc un effet plus drastique sur la digestibilité que l'augmentation de NDFS.

Il apparaît donc nécessaire de limiter la dégradation de la cellulose (source d'énergie pour les micro-organismes du rumen) par la souche de champignons pour éviter un trop fort accroissement de la teneur en lignine de la paille traitée.

L'utilisation d'organismes ligninolytiques semblerait plus appropriée (Agosin, 1985). Mais, si dans ce cas, la cellulose est quasi épargnée, conduisant à des digestibilités de l'ordre de $65-70$ p. 100 , les temps de culture sont très longs (60 à 120 jours); en outre, la teneur de la biomasse en protéines n'est pas modifiée (ZaDrazil \& BRUNNERT, 1982).

La délignification biologique épargnant l'essentiel de la cellulose est pratiquée de facon naturelle à l'image des "Palo Podrido » (bois pourris qui servent d'aliment aux bovins et aux chevaux au Chili) contaminés principalement par Ganoderma applanatum.

Sur 30 échantillons de "Palo Podrido » (à des degrés de décomposition différente) examinés par Zadrazil, Grinbergs \& Gonzalez (1982), la teneur en lignine a varié entre 32 et 1 p. 100 et la digestibilité in vitro entre 2 et 78 p. 100 . Quant à la teneur en matières azotées totales, elle est très faible (entre 0,5 et 3 p. 100). 
En revanche, comme le montrent nos résultats et ceux d'autres auteurs (IConomou, 1982 ; NoJAC, 1984), les champignons cellulolytiques enrichissent effectivement les substrats ligno-cellulosiques en protéines en un temps de culture très court ( 3 à 8 jours). Dans nos expériences, nous avons observé un temps de culture de huit jours qui semble convenir à la souche Myrothecium puisque les pertes en cellulose et en matière sèche sont faibles, la synthèse de protéines élevées ainsi que la digestibilité pour le couple pH 6-humidité 87 p. 100 (67 p. 100).

Par contre, pour Trichoderma, qui a une très forte capacité à hydrolyser la cellulose, ce temps est probablement trop long.

Outre la teneur en cellulose des échantillons traités, la teneur en protéines a un effet positif sur la digestibilité ; à l'inverse, les pertes en matière sèche au cours de la culture sont en corrélation négative avec la digestibilité (tabl. 6).

Tableau 6

Facteurs qui influencent la digestibilité des échantillons traités. Variation factors of digestibility

\begin{tabular}{|c|c|c|c|}
\hline & $\mathrm{n}$ & $\mathbf{R}$ & Signification \\
\hline Cellulose Van Soest-Cellulose & 18 & 0,73 & $\mathrm{p}<0,01$ \\
\hline Protéines - Protein $\ldots \ldots \ldots$ & 18 & 0,81 & $\mathrm{p}<0,01$ \\
\hline Lignine Van Soest - Lignin & 18 & $-0,74$ & $\mathrm{p}<0,01$ \\
\hline Pertes en MS - DM losses & 18 & $-0,80$ & $\mathrm{p}<0,01$ \\
\hline
\end{tabular}

En réalité, les pertes en matière sèche s'identifient à l'augmentation de la teneur des échantillons en lignine.

Le tableau 6 montre par ailleurs que 53, 66, 55 et 64 p. 100 des variations (R2) de la digestibilité (y) mesurée s'expliquent respectivement par la teneur en cellulose $(\mathrm{x} 1)$, en protéines $(\mathrm{x} 2)$ et en lignine $(\mathrm{x} 3)$ des échantillons ainsi que par les pertes en matière sèche en cours de culture $(\mathrm{x} 4)$. Elle peut être estimée par la régression mutiple suivante qui explique 79 p. 100 des variations.

$$
\mathrm{Y}=0,34 \times 1+1,67 \times 2-1,24 \times 3-0,07 \times 4+40,4 \pm 2,31 ; \mathrm{R}=0,891
$$

\section{Conclusion}

Quel que soit le facteur abiotique de culture (taux d'humidité et $\mathrm{pH}$ ), la digestibilité des échantillons traités avec Trichoderma a été inférieure en moyenne à celle des témoins à cause d'une forte consommation de la cellulose par l'organisme, accroissant du même coup la teneur en lignine de la biomasse. Ce phénomène a été limité pour Myrothecium. Ainsi, nous enregistrons des digestibilités élevées pour certains échantillons, notamment le pH 6-humidité 87 p. $100 \quad(67$ p. 100$)$ et le pH 5-87 p. 100 (64 p. 100), pour lesquels la teneur en protéines est maximale et la dégradation de la cellulose minimale. 
L'augmentation de digestibilité obtenue ( 8 points) est correcte mais mérite d'être améliorée, en étudiant de façon approfondie les facteurs de variation de la digestibilité : teneurs en lignine, cellulose, protéines et pertes en matière sèche au cours de la culture; nous ajouterons à ces facteurs, le temps de culture, la dose d'azote et l'inocuité pour l'animal de Myrothécium verrucaria qui apparaît comme étant plus performant que la souche de Trichoderma viride dans l'amélioration de la digestibilité de la paille.

Reçu en mars 1986.

Accepté en décembre 1986.

\begin{abstract}
Summary
Protein content and digestibility of wheat straw treated with Trichoderma viride and Myrothecium verrucaria
\end{abstract}

A semi-solid medium (moisture content 80,84 and 87 p. 100, pH 4, 5 and 6) containing two strains of hyphomycetes: Trichoderma viride and Myrothecium verrucaria was used to improve nutritive value (protein content and digestibility) of wheat straw.

After 8 days of culture, dry matter, protein and cell-wall constituent contents, dry matter losses and digestibility in sacco were measured.

The following results were obtained :

1) Van Soest cellulose content of treated straw was significantly lower than that of control untreated straw. The reduction was more marked in samples treated with Trichoderma (12 points versus 8 with Myrothecium). Lignin content was increased by 8 and 1 point, respectively with Trichoderma and Myrothecium (tabl. 2). Dry matter losses did not exceed on an average 10 p. 100 for both organisms (tabl. 3).

2) Protein content of treated straw was increased on an average by 3.3 and $4.7 \mathrm{~g} / 100 \mathrm{~g} \mathrm{DM}$, respectively with Trichoderma and Myrothecium corresponding to a total protein content of samples of 7.1 and $8.4 \mathrm{~g} / 100 \mathrm{~g}$ DM. These contents corresponded to a yield of 0.31 and 0.60 mycelian protein/g of cellulose used (tabl. 4).

3) Digestibility of Trichoderma viride - treated straw was on an average significantly lower than that of controls (54 p. 100 versus 59 p. 100). However, digestibility of Myrothecium verrucaria - treated straw was slightly higher $(61 \mathrm{p} .100)$. With the latter microorganism, digestibility increased with moisture content to reach $67 \mathrm{p} .100$ in the sample cultured at pH 6 with 87 p. 100 moisture. Myrothecium verrucaria was more efficient to treat straw than Trichoderma viride (tabl. 5).

Digestibility values changed in the same direction as protein and cellulose contents of the samples and in reverse direction for lignin content and dry matter losses. These $\mathbf{4}$ factors explained 79 p. 100 of variations.

Key words: Trichoderma viride, Myrothecium verrucaria, treated wheat straw, in sacco digestibility, protein content.

\title{
Remerciements
}

Nous remercions $\mathbf{M}^{\text {me }}$ ROQUEBERT du Muséum d'histoire naturelle de Paris qui a bien voulu identifier les deux souches de champignons et M. Tisserand de l'E.N.S.S.A.A. de Dijon pour l'intérêt qu'il porte à ce travail. 


\section{Références bibliographiques}

Agosin E., 1985. Amélioration de la digestibilité des sous-produits ligno-cellulosiques par délignification microbienne. Thèse de Docteur-Ingénieur, 109 p., Paris-Grignon.

Ben-Ghedalia D., Miron J., 1981. Effect of sodium hydroxide, ozone and sulphur dioxide on the composition and in vitro digestibility of wheat straw. J. Sci. Fd. Agric., 32, 224-228.

Borham B.E.A., Sundstøl F., Garmo Th., 1982. Studies on ammonia-treated straw. II. Fixation of ammonia in treated straw by spraying with acids. Anim. Feed. Sci. Technol., 7, 53-59.

Cordesse R., TABA Tabai M., 1981. Alimentation d'agneaux à partir de la paille traitée à l'ammoniac. I. Valeur nutritive, croissance et qualité des carcasses des animaux. Ann. Zootech., 30, 137-149.

Demarquilly C., Chenost M., 1969. Etude de la digestion des fourrages dans le rumen par la méthode des sachets de nylon; liaison avec la valeur alimentaire. Ann. Zootech., 18, 419-436.

Demeyer D.I., VervaEke I.J., 1985. Digestion dans le rumen des fourrages pauvres et procédés microbiens pour augmenter la valeur nutritive. Document O.C.D.E., Paris, 174 p.

Demeyer D., Van Nevel C., 1986. Influence of substrate and microbial interaction of efficiency of rumen microbial growth. Reprod. Nutr. Dévelop., 26, 161-179.

Dulphy J.P., Breton J., Bienaime A., Louyot J.M., 1982. Etude de la valeur alimentaire des pailles de céréales traitées ou non à la soude. I. Influence du traitement à la soude. Ann. Zootech., 31, 195-214.

Hoden A., 1972. Aspects digestifs et métaboliques de l'utilisation de l'azote non protéique par les ruminants recevant des fourrages pauvres. Rapport bibliographique D.E.A. de nutrition. Université de Clermont-Ferrand, $26 \mathrm{p}$.

Horton G.M.J., Nicholson H.H., Christensen D.A., 1982. Ammonia and sodium hydroxide treatment of wheat straw in diets for fattening steers. Anim. Feed. Sci. Technol., 7, 1-10.

IсоNомоu, D., 1982. Valorisation de divers substrats résiduels en vue de la production de protéines par Trichoderma album. Thèse de Docteur-Ingénieur, Université de Dijon, 161 p.

Kategile J.A., 1979. Performance of heifers fed on diets based on $\mathrm{NaOH}$ treated maize cobs and the effect of supplementary urea and source of carbohydrates. Anim. Feed. Sci. Technol., 4, 97-107.

Kategile J.A., Frederiksen J.H., 1979. Effect of level of sodium hydroxide treatment and volume of solution on the nutritive value of maize cobs. Anim. Feed. Sci. Technol., 4, 1-15.

Kiflewahid B., Potts G.R., Drysdale R.M., 1982. By-product utilization for animal production. I.D.R.C. 206, 158 p., Canada.

Larpent J.P., Larpent-Gourgaud M., 1970. Microbiologie pratique, 203 p., Ed. Hermann, Paris.

Lowry O.H., Rosebrough N.J., Farr A.L., Randall R.J., 1951. Protein measurement with the folin phenol reagent. J. Biol. Chem., 193, 265-275.

NoJAC I., 1984. Caractérisation et évaluation de l'aptitude de champignons filamenteux à l'enrichissement en protéines des pulpes de betterave. Mémoire d'ingénieur, Ensbana, Dijon, $23 \mathrm{p}$.

OлI U.I., Mowat D.N., 1979. Nutritive value of thermoammoniated and steam-treated maize stover. I. Intake, digestibility and nitrogen retention. Anim. Feed. Sci. Technol., 4, 177-186.

Raimbault M., 1981. Fermentation en milieu solide. O.R.S.T.O.M., Paris, 291 p.

Staron, 1984. Essais de culture de Trichoderma album sur paille brute et sur paille sodée in : L'encyclopédie nutritionnelle de l'homme, p. 308-316, INRA, Lucé.

Van Soest P.J., WINE R.H., 1967. Use of detergents in the analysis of fibrous feeds. IV. Determination of plant cell-wall constituents. J. Assos. Off. Anal. Chem., 50, 50-55.

WaAgepetersen J., Thomsen K.V., 1977. Effect on digestibility and nitrogen content of barley straw of different ammonia treatments. Anim. Feed. Sci. Technol., 2, 131-142.

Wilkinson J.M., Gonzalez S., 1978. Ensiled alkali-treatment straw. I. Effect of level and type of alkali on the composition and digestibility in vitro of ensiled barley straw. Anim. Feed. Sci. Technol., 3, 117-132. 
Williams P.E.V., MacDearmid A., InNes G.M., 1983. Anhydrous ammonia-treated whole. Crop barley for beef steers. Anim. Prod., 36, 39-45.

Xande A., 1978a. Valeur alimentaire des pailles de céréales chez le mouton: 1. Influence de la complémentation azotée et énergétique sur l'ingestion et l'utilisation digestive d'une paille d'orge. Ann. Zootech., 27, 583-599.

Xande A., 1978b. Valeur alimentaire des pailles de céréales chez le mouton : II. Influence de l'espèce, de la variété et du séjour sur le sol avant ramassage, sur la valeur alimentaire des pailles de céréales. Ann. Zootech., 27, 601-616.

Zadrazil F., Brunnert H., 1982. Solid state fermentation of lignocellulose containing plant residues with Sporotrichum pulverulentum Nov. and Dichomitus squalens (Karst) Reid. Eur. J. Appl. Microbiol. Biotechnol., 16, 45-51.

Zadrazil F., Grindbergs J., Gonzalez A., 1982. «Palo Podrido »-Decomposed wood used as feed. Eur. J. Appl. Microbiol. Biotechnol., 15, 167-171. 